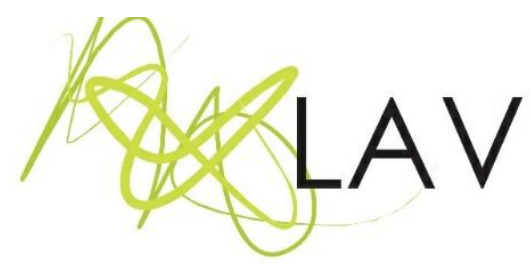

\title{
Imagens do corpo: superfícies reversíveis e marcas de resistências no brinquedo de miriti
}

\author{
IMAGES OF THE BODY: REVERSIBLE SURFACES AND RESISTANCE MARKS IN THE TOY \\ OF MIRITI
}

Joyce Otânia Seixas Ribeiroi Universidade Federal do Pará

Vilma Nonato de Brício ii Universidade Federal do Pará

\section{Resumo}

O objetivo deste artigo é refletir sobre as representações do corpo nas imagens do brinquedo de miriti, um bem cultural da cidade de Abaetetuba/Pará. Para isso, o trabalho utiliza como embasamento os estudos Culturais pós-críticos, contando com Hall (2016), Kellner (1995), Foucault (1987) e Silva (1999), entre outros. A decisão metodológica é pelo alfabetismo crítico, um procedimento emergente para a análise de imagens. Ao serem intensamente disseminadas em blogs, livros, camisetas e bolsas, as imagens da peça casal de namorados representam o corpo e o casal ideal e afetam a todos, particularmente jovens do Ensino Médio. Por constituir não apenas a cultura contemporânea, mas as subjetividades juvenis no cotidiano escolar, as imagens merecem atenção, pois mesmo representando corpos, gêneros e sexualidades hegemônicas, sendo a representação reversível, é capaz de constituir outros modos de ser e de viver.

Palavras-chave: Imagem, corpo-gênero-sexualidade, representação.

\begin{abstract}
The objective of this paper is to reflect on the representations of the body in the images of the toy of miriti, a cultural asset of the city of Abaetetuba/Pará. In this sense, we seek support in post-critical Cultural Studies, counting, among others, on Hall (2016), Kellner (1995), Foucault (1987) and Silva (1999). The methodological choice is for critical literacy, an emerging procedure for image analysis. By being intensely disseminated in blogs, books, T-shirts and handbags, the images of the couple of boyfriends represent the ideal body and couple, and they affect everyone, particularly high school youth. As it constitutes not only contemporary culture but also youth subjectivities in daily school life, the images deserve attention, because even if it represented hegemonic bodies, genders and sexualities, being its reversible representation, it is capable of constituting other ways of being and living.
\end{abstract}

Keywords: Image, body-gender-sexuality, representation. 


\section{Palavras iniciais}

Com o impacto da globalização na contemporaneidade, presenciamos a proliferação de imagens e a configuração da sociedade do simulacro. Entre tais impactos, é perceptível a presença das tecnologias da comunicação no cotidiano das pessoas, o que alterou seus modos de ser e sentir, ao disseminar uma infinidade de imagens. Essa nova feição do mundo impõe outras habilidades de leitura, pois, apesar da leitura de textos escritos ainda ser fundamental, deixou de ser a única demandada. Hoje, a leitura de imagens é uma condição para uma postura crítica no nosso lugar, pressionado por códigos globais e locais.

Tendo isso em mente, neste artigo, nosso objetivo é refletir sobre as representações do corpo disseminadas pelas imagens do brinquedo de miriti, um bem cultural que ancora uma bicentenária tradição e um patrimônio cultural. Perseguindo esse objetivo, buscamos apoio nos Estudos Culturais pós-críticos, contando, entre outros, com Hall (2016), Kellner (1995), Foucault (1987) e Silva (1999), que nos auxiliam na tarefa de proceder a uma leitura crítica das imagens.

O referente para tais imagens são os brinquedos de miriti, artefatos culturalmente centrais para Abaetetuba, uma cidade localizada no interior do estado do Pará. Para discutir corpo-gênero-sexualidade, focaremos em uma peça considerada tradicional, o casal de namorados, que tem sido intensamente divulgado por meio de imagens que afetam a todos, particularmente, aos jovens. Tais imagens estão presentes em camisetas, bolsas e livros paradidáticos, e, por isso, merecem a atenção de professores e professoras, na medida em que constituem os sujeitos, ao representar o corpo ideal e ensinar modos de ser e de viver.

Há várias perspectivas analíticas de imagens, contudo, decidimos pelo alfabetismo crítico proposto por Kellner (1995), pois o autor foca na crítica ideológica, na análise da política de representação, em dimensões de gênero, de raça, de classe e de sexualidade nas relações sociais. Seu propósito é a compreensão do poder e da dominação, questionando, assim, as abordagens relativistas e apolíticas sobre educação midiática. Uma condição para levar a efeito o alfabetismo crítico é a ampliação da noção de texto e de análise textual, o que impõe considerar ferramentas como contexto social, controle e resistência. Outro termo ampliado é o alfabetismo, que, aqui diz respeito à habilidade para leitura de imagens, ou seja, a interpretação de códigos e signos contidos nas imagens. 
Para Kellner (1995) e Kellner e Share (2008), as imagens são textos intencionalmente produzidos para transmitir significados e valores de modo a constituir identidades e subjetividades. Cada imagem tem potencialidade para manipular ou esclarecer em qualquer dimensão social, e aqui se inclui a escolarização, que é vital para professores e professoras, no sentido de ensinar os estudantes a ler imagens criticamente. Porém, há desafios no alfabetismo crítico, entre eles, os da perspectiva metodológica, pois acaba sendo um procedimento aberto e experimental, um procedimento em formação, sem pressupostos e princípios estabelecidos. Desse modo, requer envolvimento e sensibilidade para inserção em diferentes de campos de saber, percepção aguçada das imagens e significados, tudo com vistas a decifrar criticamente suas mensagens complexas em benefício dos grupos marginalizados.

Para dar conta do objetivo indicado, organizamos o artigo de modo a iniciar descrevendo Abaetetuba e a cultura do miriti. Em seguida, apresentamos a peça casal de namorados e as representações que disseminam. A partir daqui, mostramos as representações de um grupo de estudantes sobre a peça em análise, como suporte para o debate sobre diferença, representação e reversibilidade para outra arte de ser na escola.

\section{Abaetetuba e a cultura do miriti}

Abaetetuba está localizada a poucas horas de Belém, a capital do estado do Pará ${ }^{1}$, e sua espacialização é semelhante à de tantos outros municípios do interior do estado. Abaetetuba é uma cidade híbrida, uma cidade-campo, com marcas tanto da dinâmica do campo e seu modo de vida caboclo (GOMES, 2013), quanto dos signos da cultura globalizada. Neste segundo aspecto, a interação com os signos e imagens das mídias se dá em razão do contato cotidiano com a capital do estado, bem como via mídias digitais, Internet e redes sociais. Curioso é o deslocamento identitário permanente, pois a cidade é representada por voláteis representações ${ }^{2}$, a depender do cenário econômico ou cultural do momento. Desse modo, mais recentemente, a cidade é representada como a capital mundial do brinquedo de miriti.

\footnotetext{
1 No censo IBGE (2020), consta que a cidade tem população de 141.100 habitantes, sendo sua principal atividade econômica, o comércio.

2 Há outras representações, como: terra da cachaça, cidade das olarias, cidade das drogas, cidade da carpintaria naval, terra das cestarias e cidade das bicicletas.
} 
Os artefatos de miriti são popularmente chamados de brinquedos de miriti, contudo, em tempos de globalização já não servem ao lúdico, pois agora são objetos de decoração e de exposição. Produzidos há mais de 200 anos, essa bicentenária tradição contém vários aspectos como a relação com o Círio de Nazaré, a produção generificada ${ }^{3}$, a estética da miniaturização e os temas tradicionais. Dada a limitação do espaço, descreveremos brevemente os dois últimos. Como sugere a expressão, a estética da miniaturização refere-se a peças em escala reduzida, em geral, entre 5 e $30 \mathrm{~cm}$, modelados com abundância de detalhes e com colorido vibrante. A estética da miniaturização é parte de uma estratégia discursiva que intenciona engrandecer o significado, na medida em que o todo pode ser apreendido em uma única mirada, já que as peças cabem na palma da mão (CANCLINI, 1998).

A modelagem é orientada por temas tradicionais e temas inovadores ${ }^{4}$. Os temas tradicionais, os preferidos do público, representam aspectos do cotidiano da vida ribeirinha: a palafita ${ }^{5}$ representa a moradia; a canoa e os barcos representam o transporte e o trabalho; o açaí, a farinha e a garrafa de aguardente representam a alimentação; a roda gigante e a barquinha representam o lazer nas festividades religiosas; a berlinda de Nossa Senhora de Nazaré representa a religiosidade católica; pássaros, onças, cobras e peixes representam a exuberante fauna amazônica; e, por fim, o casal de namorados representa o afeto.

Os temas tradicionais fazem do brinquedo de miriti um artefato-síntese do regionalismo, da identidade Amazônida, pois representa aspectos do cotidiano e da cultura ribeirinha. O brinquedo de miriti foi certificado como patrimônio cultural imaterial do estado do Pará, o que trouxe a necessidade de um palco destinado à sua exposição, ao que Canclini (1998) denomina de teatralização. A exposição das peças de miriti é permanente em diversos espaços sociais, como igrejas, escolas, universidades, bancos, hospitais, praças e também nas casas dos abaetetubenses; nestes palcos são expostos móbiles de pássaros, barcos, quadros com animais da região, peças que fazem parte da decoração para serem vistas e admiradas. Porém, com as demandas da sociedade globalizada marcada pela saturação de imagens (BAUDRILLARD, 1999), a teatralização ganha outros palcos como diferentes mídias: livros, revistas, portais, redes sociais, além de roupas e acessórios. As imagens dos brinquedos de miriti estão por toda parte.

\footnotetext{
3 Produção generificada é um modo de organizar a produção dos brinquedos nos ateliês; consiste na distribuição de tarefas por gênero: os homens fazem o trabalho considerado bruto (cortar, lixar) e as mulheres fazem o trabalho supostamente leve (pintar).

${ }^{4}$ Temas inovadores são os da cultura globalizada e tecnológica: bicicletas, rádio, televisão, computadores, motocicletas, bonecos de personagens Disney e outros desenhos animados, personagens super-heróis de filmes de sucesso.

5 Palafita é uma casa construída sobre as águas ou na beira de rios.
} 


\section{A peça casal de namorados e a imagem do casal heteronormativo}

Uma das peças amplamente divulgada é o casal de namorados. Esta consiste na representação de um homem e uma mulher que estão abraçados simulando um beijo. Nas imagens 1, consta em um livro, a 2 em um blog de viagens e a imagem 3 em uma sacola. Em todas as imagens, é recorrente o casal de namorados heteronormativo. As peças permitem perceber as marcas de gênero na plástica dos corpos masculinos e femininos, como o corte dos cabelos e as roupas. Como é possível notar, o corpo masculino é representado com cabelos curtos, calças e camisa com mangas curtas; o corpo feminino é representado com cabelos longos, vestidos ou saias.

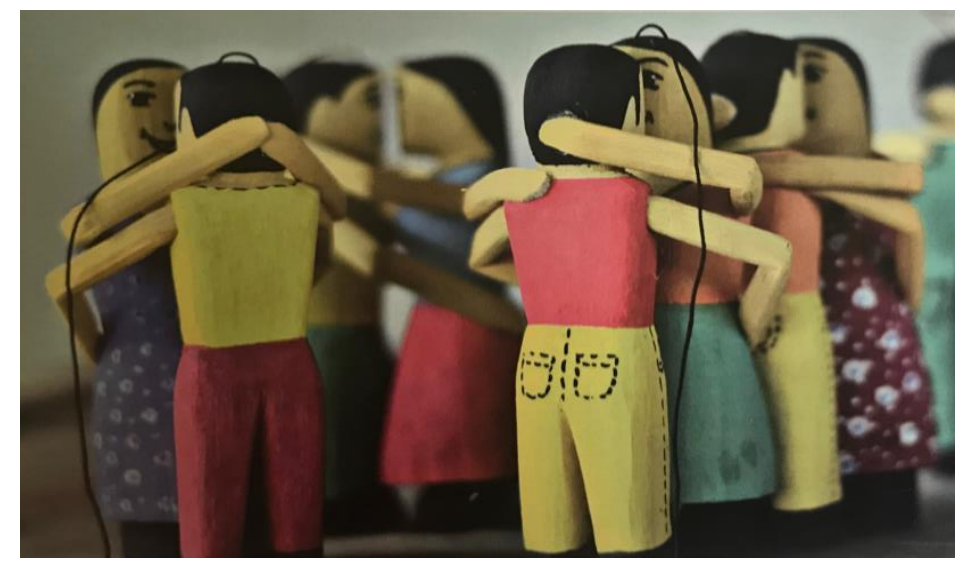

Imagem 1

Fonte: Pará; Contente, 2018.

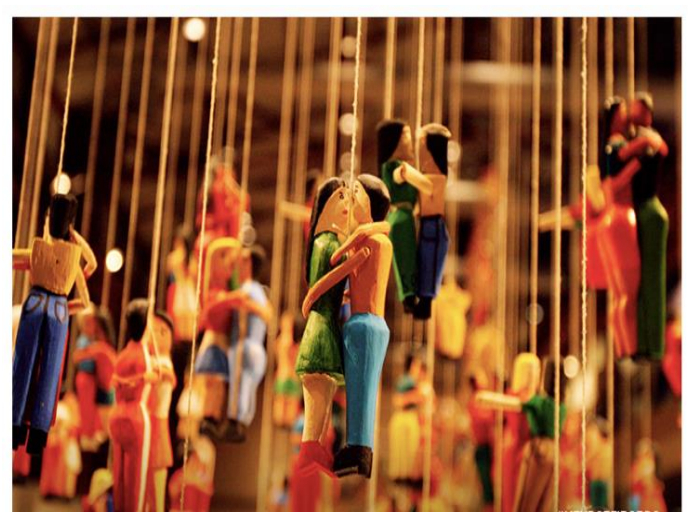

Imagem 2

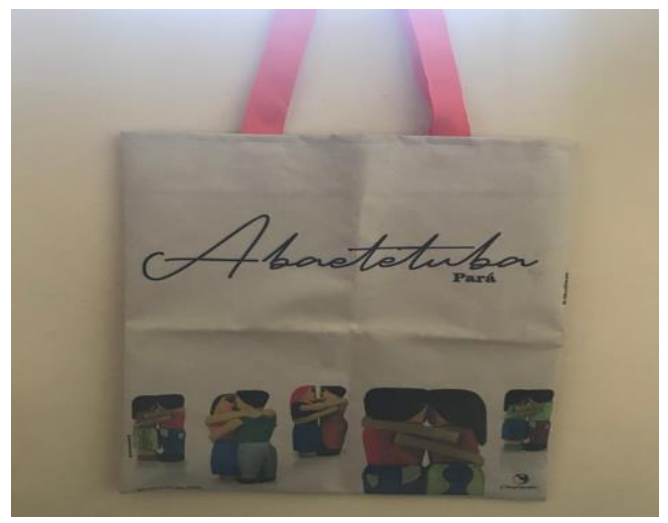

Imagem 3 
Com esta plástica, as imagens remetem aos gêneros hegemônicos, veiculando significados sobre o que é aceitável para homens e mulheres em relação ao vestuário, ao corte de cabelos e ao par romântico, sendo possível identificá-los na primeira mirada. É assim em razão da sociedade controlar o indivíduo por meio do corpo, na medida em que faz agir sobre ele um conjunto de dispositivos com a finalidade de disciplinamento, para levar o sujeito ao governo de si e ao cuidado de si (FOUCAULT, 1987). As imagens reproduzidas nesse em vários outros artefatos participam dos jogos de poder, ao representar padrões de classe, raça e gênero.

O traço distintivo do poder é que alguns homens possam mais ou
menos integralmente determinar a conduta de outros homens -
ainda que não de maneira exaustiva ou coercitiva [...] O governo
dos homens pelos homens - formem eles grupos modestos ou
importantes, quer se trate do poder dos homens sobre as
mulheres, dos adultos sobre as crianças, de alguma classe sobre a
outra, ou de uma burocracia sobre uma população - supõe uma
determinada forma de racionalidade e não uma violência
instrumental [...] a questão é [então]: como são racionalizadas as
relações de poder? (FOUCAULT, 1996, p. 64-65).

Os aspectos do vestuário da peça casal de namorados produzem relações de poder e marcam a interseccionalidade entre classe, raça e gênero, ao representar as peças de roupas em cores, modelos e tipos diferentes. Geralmente azul, amarelo, vermelho, verde são as cores das roupas dos homens; vermelho, verde, amarelo, rosa e também as estampas são as roupas das mulheres. As peças de roupas são comuns à burguesia e à classe trabalhadora, entretanto, nas peças de casal de namorados, os modelos remetem ao tipo de vestimenta da classe trabalhadora, sendo as mais comuns calças, bermudas, camisa, saia e blusa. A roupa como simples vestuário, e não como expressão de estilo ou moda, para as classes populares é produzida em série, marcada pela informalidade e simplicidade (LYPOVETSKY, 2009), definindo um modo de se vestir a partir da década de 1920, utilizando malhas, tecidos e materiais mais baratos.

Nas imagens 1, 2 e 3, as peças do casal de namorados disseminam normas que se constituem em princípios organizadores para o cuidado com o corpo, tendo como objetivo a homogeneização-diferenciação de seus traços. No processo de homogeneização, o roteiro é o mesmo tanto para o feminino quanto para o masculino, de modo que as mulheres e homens devem vestir-se e pentear-se conforme o considerado

\footnotetext{
${ }^{6}$ Este blog oferece serviços de viagens, disponibilizando vários serviços, divulgados em redes sociais como o Facebook, Instagram, Linkedin e YouTube. Cf: <www.rdcviagens.com.br>.
} 
adequado ao seu gênero. Na diferenciação, o roteiro difere para mulheres e homens. Assim, a roupa produz sentido sobre o corpo masculino e o feminino, na medida em que expressa a diferença, de modo que existem roupas para heterossexuais, homossexuais, crianças, jovens, velhos, negros, ricos e pobres (STALLYBRAS, 1999). O outro dispositivo de diferenciação é o penteado; o corte de cabelos identifica cada gênero e funciona como um sinal visual, pois sempre houve uma estética diferenciada para eles e elas, almejando a identificação inequívoca. Os penteados são definidos não apenas para homens e mulheres heterossexuais, pois se levarmos em conta outros marcadores como raça-etnia, sexualidade e classe, a lista de regras será bastante extensa. Hoje há muitos penteados, cabelos multicoloridos, e o mais comum em tempo de influência midiática é seguir a tendência das celebridades.

As imagens do casal de namorados disseminadas representam o erotismo heteronormativo, porque insinuam a reprodução e a continuidade da vida, no encontro dos corpos e na busca pela superação do isolamento e da solidão (BATAILLE, 1987); o encontro erótico dos corpos almeja a reprodução da vida por temor da morte (BAKHTIN, 1987). Tais aspectos ficam encobertos por uma aura de beleza e de inocência, porém, ao circular nos mais diversos espaços sociais, disseminam representações que reforçam a economia do corpo e certos modos de ser. O sujeito olhante à semelhança de um voyeur será inevitavelmente afetado por certos significados e representações, podendo aceitáIos, contestá-los ou traduzi-los (FOUCAULT, 1998).

\section{O sujeito olhante: jovens escolares e suas representações}

A partir deste tópico, ocupar-nos-emos, de modo breve, com a recepção imagética de certo sujeito olhante, um grupo de estudantes de Ensino Médio, para saber com representam a peça casal de namorados. Considerando a ampla veiculação das imagens desta peça, bem como as representações que disseminam, no ano de 2017, realizamos um levantamento em três escolas de Ensino Médio da cidade: Escola Estadual Benvinda Pontes, Escola Estadual Basílio de Carvalho e Escola Estadual Bernardino Pereira de Barros. Naquela oportunidade, aplicamos questionários com perguntas abertas a grupos de professores, aos gestores e a grupos de estudantes. Todas as perguntas se referiam ao brinquedo de miriti.

Até o momento, não havíamos dado atenção ao conjunto de relatos dos estudantes, tendo focado mais detidamente nos relatos dos docentes e da equipe 
técnica. Porém, provocadas pela problemática das imagens e representações, voltamos aos relatos dos alunos e alunas. Vários grupos de jovens aceitaram colaborar com o levantamento que se estendeu por três meses, nos turnos vespertino e noturno. Os estudantes do Ensino Médio dessas três escolas, em geral, estão na faixa etária de 15-24 anos, são rapazes e moças das classes populares, em sua maioria moram nos bairros periféricos - muitos moram no campo -, e se declaram católicos e heterossexuais. A maior parte do grupo declarou que gosta de morar em Abaetetuba, sendo que alguns reconhecem o brinquedo de miriti como um artesanato que gera renda e garante a sobrevivência; outros consideram que o brinquedo de miriti é uma expressão artística que valoriza a cidade, divulgando-a para o mundo, promovendo reconhecimento, respeito e pertencimento, porque "só tem aqui"; condição que os deixa orgulhosos. Em uma das perguntas do questionário, indagamos sobre como viam a peça casal de namorados e, após sistematização, concluímos que a veem como um modelo social aceito. Eis algumas respostas que sintetizam esta ideia:

Acho lindo, é como um modelo... sonho em me casar, ter uma casa e filhos (Michele, E.E. Benvinda Pontes).

É o retrato de um casal, como meus pais ... meus avós (Aline, E.E. Bernardino Pereira de Barros).

Um par perfeito, feitos um para o outro (Débora, E.E. Bernardino Pereira de Barros).

Acho que é um brinquedo que fala de amor e de felicidade (Patrícia, E.E. Benvinda Pontes).

Fala da nossa vida, de ter uma família para cuidar (Rodrigo, E.E. Basílio de Carvalho).

Acho que fala da vida real, de ter família e de ter futuro (Carlos, E.E. Basílio de Carvalho).

A representação será aqui entendida como uma inscrição ou marca, o que a faz ser concreta e visível, adquirindo sentido ao ser colada a certa cadeia de significados (SILVA, 1999). A noção de representação em Hall (2016) é entretecida no solo da abordagem construtivista com o apoio de Ferdinand de Saussure e de Michel Foucault. A experiência do mundo é fundamental, pois é a interação social que permite elaborar os sentidos que regulam práticas, condutas e identidades em certa cultura.

Nessa abordagem, Saussure contribui para pensar como os sentidos são produzidos pela linguagem (escrita, falada, imagética), e como operam por sistemas de representação, responsáveis por ligar o sentido e a linguagem em certa cultura. A 
contribuição de Foucault está no conceito de discurso e sua permanente relação com o poder e com o sujeito. Um aspecto central do conceito de representação é o fato de um signo nunca ser fixo, pois é traduzido em função do espaço-tempo. Outro aspecto importante desse conceito é a possibilidade de analisar os estereótipos por meio do funcionamento das representações.

Considerando imagens e experiências no espaço-tempo da escola, as representações dos estudantes reafirmam significados hegemônicos. Uma mirada rápida sobre a peça casal de namorados (imagens 1, 2 e 3) pode não permitir a percepção da volatilidade das representações em razão de serem adequadas ao referente. E essa suposta adequação ao referente restringe a pergunta sobre a natureza do objeto (o que é isso?), pois as marcas permitem identificar um casal heterossexual. Essa é a função da imagem, bem como de um quadro ou de um desenho e, neste caso, das imagens da peça casal de namorados, ou seja, representar, deixando "[...] aparecer sem equívocos nem hesitação aquilo que [...] representa" (FOUCAULT, 1998, p. 20). Neste caso, como o corpo é o responsável imediato pela identificação dos gêneros, a peça apresenta as marcas do referente em toda sua superfície, disseminando os princípios organizadores da cultura de gênero, sendo desnecessária qualquer explicação adicional, pois o reconhecimento está assegurado (FOUCAULT, 1998).

A proliferação das imagens da peça casal de namorados nas mais diversas mídias e espaços sociais alteram o cotidiano e a subjetividade juvenil, na medida em que suas experiências são atravessadas por uma infinidade de signos. Analisando essa cartografia, Baudrillard (1995) argumenta que as experiências cotidianas e as interações sociais foram definitivamente transformadas nos dias atuais, por meio da cultura da representação, a ponto de denominar esta sociedade de sociedade simulacional. Nesta, as imagens (de sapatos, roupas, de carros e de corpos masculinos e femininos) e os signos (como o de beleza, por exemplo) se tornam a própria realidade, e um exemplo disso é o fato das pessoas manifestarem sua preferência pelo fascínio e o encantamento da imagem no detrimento do referente; para Baudrillard (1995), quando isso ocorre, temos a hiper-realidade, na qual os significados moldam o poder em signos e aparências, não fornecendo a realidade, mas vertigem da realidade, impedindo, por conta disso, a resistência.

Nessa perspectiva, a imagem como um artefato cultural de produção de sentido é parte integrante de uma política cultural que satura a cultura com significados que passam a ser o discurso público dominante, e se refletem em marcas linguísticas 
materiais (KELLNER, 1995), nos estilos de vida e nas condutas de gênero e de sexualidade. Silva (1999) argumenta que as imagens transmitem uma economia do afeto e do desejo que incide sobre corpos e mente, ensinando o que o sujeito deve pensar, falar, fazer e desejar. Por meio de imagens, processa-se a disseminação de uma poética que inclui valores, ideias e emoções capazes de modelar condutas desejáveis socialmente.

Assim, mesmo que os alunos e alunas representem a peça casal de namorados como o casal supostamente ideal por identificá-los com o real, mostraremos, a seguir, que outras peças marcadas pela diferença estão sendo modeladas. A partir disso, outras plásticas dos corpos e afetos são expressos em peças de casal de namorados pouco visibilizadas. E se começássemos a investir no endereçamento das imagens abaixo?

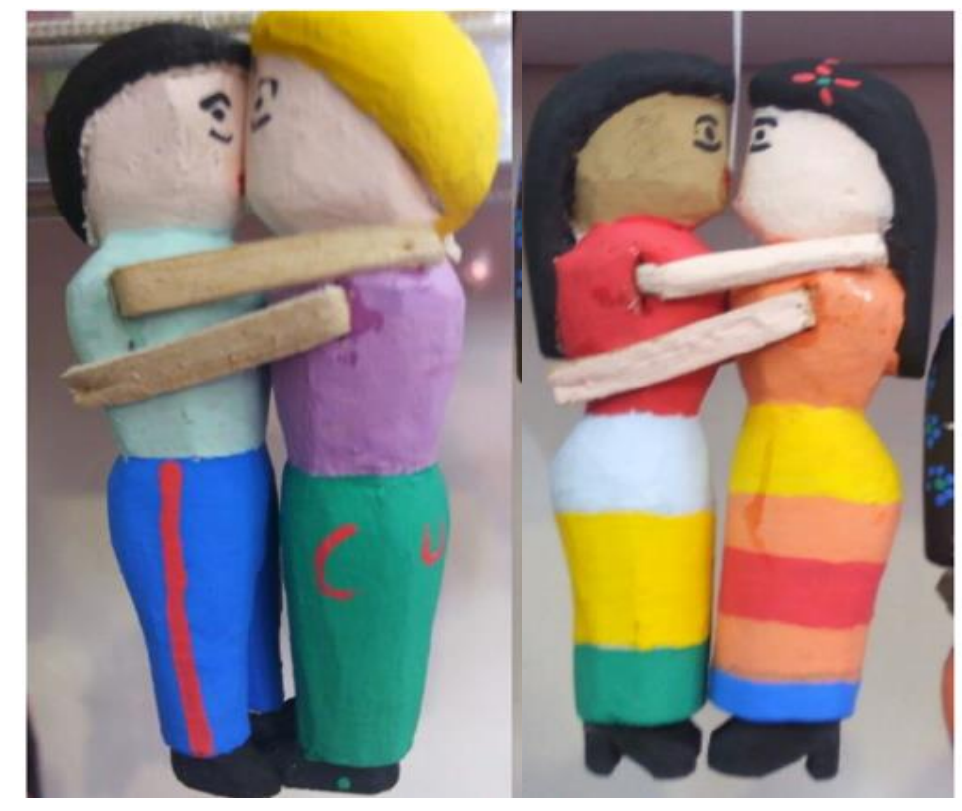

Imagem 4

Fonte: Sarges (2019)

$\mathrm{Na}$ imagem 4, há dois casais de namorados e, como é perceptível, eles representam a diferença étnica, de gênero e de sexualidade. Apesar dos corpos masculinos e femininos apresentarem a plástica de gênero hegemônica, com cabelos longos e vestidos para elas e cabelos curtos e calças para eles, há arranjos inusitados considerados abjetos, com um casal de mulheres e um casal de homens LGBT e interraciais.

Esses novos arranjos podem ser refletidos pelos Estudos Culturais pós-críticos, porque, mesmo considerando que a sociedade ocidental está saturada por imagens, há a 
possibilidade de crítica e de intervenção politicamente comprometida direcionadas à mudança cultural. Nessa perspectiva, é preciso estranhar o familiar para desconstruir as imagens e representações, pois não são desprovidas de intencionalidade, já que, por meio delas, a mídia e a publicidade não apenas vendem coisas, mas disseminam valores e identidades, ensinando jovens a serem consumidores (GIROUX, 2003). Silva (1999) concorda com esse argumento, destacando que tem havido contestação contra os muitos modos dominantes de representação dos corpos e das identidades, em razão de pretenderem representar a totalidade do humano. Uma das razões para tal é a própria natureza da noção de representação - aberta e instável -, que a faz implodir as fronteiras do realismo, para trilhar tateante o solo movediço de outra epistemologia de base discursiva, social e histórica. A outra razão é a capacidade de resistência.

A representação está ancorada em significados voláteis, o que impede a contenção de sentidos e dispara a reversibilidade, como bem indica Foucault (1987, 1998). Dessa perspectiva, a despeito da segurança do reconhecimento, não é um casal de namorados, mas apenas uma imagem do corpo e do desejo. Afirmamos isso devido ao fato dos signos e das representações sobre os corpos não serem fechados, dado que o corpo é provisório, porque é um produto da cultura (GOELNNER, 2003), logo, é passível de intervenções variadas, resistindo de muitas e variadas formas, aceitando, contestando, negociando e traduzindo significados e representações. Assim, a imagem fixa do corpo é uma ficção, pois entre os traços e o referente há superfícies reversíveis, trincadas por atravessamentos múltiplos que tornam o referente complexo, fluído, impedindo a fixidez (SCOTT, 1995).

Ainda que uma peça que representa um casal homoafetivo e interétnico seja considerada abjeta devido à força da cultura de gênero que valoriza a continuidade da vida, para Butler (1999), o controle do sujeito da ação não é absoluto, e, para Louro (2004), a imposição da matriz heterossexual também deixa espaço à resistência. As fissuras nos signos das imagens tornam parcial o controle do sujeito e da sociedade, abrindo espaço para a reversibilidade. Ou seja, os alunos e alunas são capazes tanto de aceitar, como de contestar, negociar e traduzir significados.

\section{A escola, os sujeitos e uma poética outra das imagens e dos artefatos culturais}

A peça casal de namorados da imagem 4 ainda não circula amplamente disseminando outros corpos e outros afetos. Mas é possível, fazê-la circular no cotidiano 
escolar, inventando espaços para envolver os estudantes em experiências com a diferença, de modo a não silenciar a multiplicidade de vozes e afirmar o discurso dominante (GIROUX; MCLAREN, 1995). Se a peça casal de namorados representa corpos e afetos heteronormativos que constituem a juventude escolar abaetetubense, podem também representar a diferença e constituir outros discursos sobre as identidades masculinas e femininas.

Porém, é preciso repensar a própria noção de pedagogia para intervir e aproveitar o espaço escolar trincado para produzir significados outros. Pensá-la como prática cultural, considerando que há uma "[...] pedagogia em qualquer lugar em que o conhecimento é produzido, em qualquer lugar em que existe a possibilidade de traduzir a experiência e construir verdades, mesmo que essas verdades pareçam irremediavelmente redundantes, superficiais e próximas ao lugar-comum" (GIROUX; MCLAREN, 1995, p. 144). Um dos focos de uma pedagogia cultural é a poética das imagens, ou seja, uma preocupação com a educação do olhar, de modo a pensar nas imagens e nos seus efeitos sobre os sujeitos (ANDERSON; CASTRO, 2012).

É preciso considerar tanto as imagens das peças do casal ideal quanto as peças marcadas pela diferença, e inseri-las no espaço escolar para que integrem os processos educativos. É imperativo ressuscitar os saberes subjugados (FOUCAULT, 2008) que não fazem parte do processo de formação no Ensino Médio. Assim, o brinquedo de miriti participará ativamente da política de verdade em torno de representações, pois a "[...] verdade é deste mundo; ela é produzida nele graças a múltiplas coerções e nele produz efeitos regulamentados de poder" (FOUCAULT, 1979, p. 12).

Como um artefato cultural, o brinquedo de miriti não está fora das relações de poder que produz verdades sobre identidades, gênero, raça, sexualidade, corpo etc. FOUCAULT (1979) comenta que

Cada sociedade tem seu regime de verdade, sua 'política geral' de
verdade: isto é, os tipos de discurso que ela acolhe e faz funcionar
como verdadeiros; os mecanismos e as instâncias que permitem
distinguir os enunciados verdadeiros dos falsos, a maneira como se
sanciona uns e outros; as técnicas e os procedimentos que são
valorizados para a obtenção da verdade; o estatuto daqueles que
têm o encargo de dizer o que funciona como verdadeiro
(FOUCAULT, 1979, p. 12).

Entretanto, no jogo discursivo que produz verdades, o brinquedo de miriti não possui estatuto de conhecimento universal, logo, não integra o cânone, permanecendo subjugado às margens da cultura, da educação e da pedagogia. 
Em nossas sociedades, a 'economia política' da verdade tem cinco características historicamente importantes: a 'verdade' é centrada na forma do discurso científico e nas instituições que o produzem; está submetida a uma constante incitação econômica e política (necessidade de verdade tanto para a produção econômica, quanto para o poder político); é objeto, de várias formas, de uma imensa difusão e de um imenso consumo (circula nos aparelhos de educação ou de informação, cuja extensão no corpo social é relativamente grande, não obstante algumas limitações rigorosas); é produzida e transmitida sob o controle, não exclusivo, mas dominante, de alguns grandes aparelhos políticos ou econômicos (universidade, exército, escritura, meios de comunicação); enfim, é objeto de debate político e de confronto social (as lutas 'ideológicas') (FOUCAULT, 1979, p. 13).

O brinquedo de miriti está situado no entre-lugar do discurso científico, da produção econômica, da circulação e do consumo, do controle das instituições, das lutas sociais, participando da 'economia política da verdade' e esquivando-se do olhar inquisidor do 'colonizador'. Desse entre-lugar, evidencia-se "[...] as fronteiras enunciativas de uma gama de outras vozes e histórias dissonantes, até dissidentes mulheres, colonizados, grupos minoritários, os portadores de sexualidades policiadas" (BHABHA, 1998, p. 24). Essas outras vozes e histórias dão visibilidade às diferenças, que não podem ser negadas devido ao fato de ocuparem o mesmo espaço (BHABHA, 1998).

Assim, o brinquedo de miriti contribui com a dinâmica de produção da diferença cultural ao confrontar a cultura local com a cultura global, o conhecimento científico com os saberes da experiência, as poéticas das imagens, produzindo modos de repensar as identidades, transformando-as e possibilitando concebê-las como um vir a ser, em um processo cambiante de constituição de singularidades.

O objetivo da diferença cultural é rearticular a soma do conhecimento a partir da perspectiva da posição de significação da minoria, que resiste a totalização - a repetição que não retornará como o mesmo, o mesmo-na-origem que resulta em estratégias políticas e discursivas, nas quais acrescentar não soma, mas serve para perturbar o cálculo de poder e saber, produzindo outros espaços de significação subalterna. [...] A diferença cultural introduz no processo de julgamento e interpretação cultural aquele choque repentino do tempo sucessivo, não sincrônico, da significação, ou a interrupção da questão suplementar (BHABHA, 1998, p. 228).

Ao produzir diferenciação cultural, o brinquedo de miriti impede o processo de totalização da cultura. Essa visibilidade dada pelo brinquedo de miriti à cultura abaetetubense não se limita a 'dar a ver', mas produz outra 'visão' da cultura local, não na perspectiva da diversidade ou da tolerância, mas de ruptura dos binarismos que 
produzem comparações e exclusões do outro, desconsiderando a singularidade dos processos disjuntivos de construção das diferenças culturais.

A produção de campos de força na perspectiva ética e estética não é simples ou fácil, na medida em que o brinquedo de miriti representa os corpos e o afeto socialmente aceitos. Porém, não sendo fixos, a partir da diferença, representações, corpos e sujeitos são capazes de romper fronteiras e de promover fissuras nas relações de saber-poder, reinventando formas de pensar, de agir e de estar no mundo.

\section{Considerações provisórias}

Encerramos provisoriamente concordando que a sociedade do simulacro contemporânea experimenta a proliferação de imagens, em razão das tecnologias da comunicação cada vez mais acessíveis em todos os lugares. Essa condição demanda o alfabetismo crítico nos múltiplos espaços sociais, entre os quais, a escola, com vista à leitura de imagens e de representações a partir das diferenças.

Os brinquedos de miriti são duplamente centrais para Abaetetuba, de modo que as imagens de uma das peças preferida pelo público, o casal de namorados, circula amplamente em várias mídias. A peça casal de namorados, em geral, representa um casal heteronormativo e dissemina normas para o cuidado com o corpo, a partir de um roteiro homogeneizador que inclui o par ideal.

Ocorre que essas imagens disseminam representações que afetam a toda a sociedade, especialmente, jovens escolares do Ensino Médio de Abaetetuba, que representam a peça analisada como a expressão do casal ideal, o que, em certa medida, apaga a diferença. Contudo, imagens, representações e corpos não são voláteis, possíveis de ser estranhados, contestados e traduzidos.

Concluir isso foi possível com base em Foucault (1987), Hall (2016) e Silva (1999), pois a representação, para esses autores, é um processo indeterminado, no qual pode haver resistência e reversibilidade. Entre os traços e o referente há superfícies maleáveis, porque os atravessamentos de classe, de gênero, de sexualidade e de etnia trincam sua superfície, produzindo imagens outras do casal de namorados, que mesmo consideradas abjetas, evidenciam a diferença e outros modos de ser. 


\section{Referências}

BAKHTIN, M. Cultura Popular na Idade Média: o contexto de François Rabelais. Tradução de Yara F. Vieira. São Paulo: Hucitec/UNB, 1987.

BATAILLE, G. O erotismo. Tradução de Antonio Carlos Viana. Porto Alegre: L\&PM, 1987.

BHABHA, H. K. O local da cultura. Belo Horizonte: Editora UFMG, 1998.

BAUDRILLARD, J.-F. Sociedade do consumo. Rio de Janeiro: Elfos, 1995.

BUTLER, J. Problemas de gênero: feminismo e subversão da identidade. Tradução de Renato Aguiar. Rio de Janeiro: Civilização Brasileira, 2003.

CANCLINI, N. G. Culturas híbridas: estratégias para entrar e sair da modernidade. Tradução de Heloísa Cintrão e Ana Regina Lessa. 2. ed. São Paulo: Edusp, 1998.

FERRARI, A. N; CASTRO, R. P. de. Política e poética das imagens: implicações para o campo da Educação. In: FERRARI, A.; CASTRO, R. P. de. (Orgs.). Política e poética das imagens como processos educativos. Juiz de Fora: Ed. UFJF, 2012.

FOUCAULT, M. Microfísica do poder. 2. ed. Rio de Janeiro: Graal, 1979.

FOUCAULT, M. Vigiar e punir. 27. ed. Petrópolis: Vozes, 1987.

FOUCAULT, M. Isso não é um cachimbo. 3. ed. Rio de Janeiro: Paz e Terra, 1998.

FOUCAULT, M. A Ordem do Discurso. São Paulo: Loyola, 1996.

FOUCAULT, M. Arqueologia das ciências e história dos sistemas de pensamento. Organização e seleção de textos Manoel Barros da Motta; Tradução de Elisa Monteiro. 2. ed. Rio de Janeiro: Forense Universitária, 2008 (Ditos e Escritos; II).

GIROUX, H. Atos impuros: a prática política dos Estudos Culturais. Tradução de Ronaldo Cataldo Costa. Porto Alegre: Artmed, 2003.

GIROUX, H.; MCLAREN, P. Por uma pedagogia crítica da representação. In: SILVA, Tomaz T.; MOREIRA, A. F. (Orgs.). Territórios contestados: O currículo e os novos mapas políticos e culturais. Petrópolis: Vozes, 1995.

GOELLNER, S. V. A produção cultural do corpo. In: LOURO, G. L.; NECKEL, J. F.; GOELLNER, S. V. (Orgs.). Corpo, gênero e sexualidade: um debate contemporâneo na educação. Petrópolis: Vozes, 2003.

GOMES, J. da S. Cidade da arte: uma poética da resistência nas margens de Abaetetuba. Tese de Doutorado. Belém: PPGCS/IFCH/UFPA, 2013.

HALL, S. Cultura e representação. Rio de Janeiro: Apicuri, 2016.

KELLNER, D.; SHARE, J. Educação para a leitura crítica da mídia, democracia e radical e a reconstrução da educação. Educação e Sociedade, Campinas, v. 29, n. 104, out., 2008.

Revista Digital do LAV - Santa Maria - vol. 13, n. 2, p. 220 - 235 - mai./ago. 2020 ISSN $1983-7348$ 
KELLNER, D. Lendo imagens criticamente: em direção a uma pedagogia pós-moderna. In: SILVA, T. T. (Org.). Alienígenas na sala de aula: uma introdução aos estudos culturais em educação. Petrópolis: Vozes, 1995.

LIPOVETSKY, G. O Império do efêmero: a moda e seu destino nas sociedades modernas. São Paulo: Cia de Bolso; Companhia das Letras, 2009.

LOBATO, L. S. O currículo e seus efeitos na subjetividade de uma mulher-artesã do miriti. Dissertação (Mestrado), PPEB/NEB/UFPA. Belém, 2019.

LOURO, G. L. Um corpo estranho: ensaios sobre sexualidade e teoria queer. Belo Horizonte: Autêntica, 2004.

PARÁ, C.; CONTENTE, F. Miriti: mãos que tecem sonhos. Belém: Grupo Olhar Fotográfico, 2018.

RIBEIRO, J.; SARGES, L.; ALEXANDRE, J. Brinquedo de miriti: a força pedagógica da cultura local no currículo. Nuances: estudos sobre Educação, Presidente Prudente, v. 28, n. 2, p. 227-245, mai./ago., 2017.

SILVA, T. T. O currículo como fetiche: a poética e a política do texto curricular. Belo Horizonte: Autêntica, 1999.

SCOTT, J. Gênero: uma categoria útil de análise histórica. Educação \& Realidade, Porto Alegre, v. 20, n. 2, jul./dez., 1995.

STALYBRASS, P. O casaco de Marx: roupas, memórias, dor. Belo Horizonte: Autêntica, 2000.

\footnotetext{
' Professora de Didática da FAECS/Campus Universitário de Abaetetuba/UFPA. Professora do PPGCITI, linha de pesquisa Identidades: linguagens, práticas e representações. Líder do Gepege/CNPq.

ii professora de Planejamento Educacional na FAECS/Campus Universitário de Abaetetuba/UFPA. Professora do PPGCITI, na linha de pesquisa Identidades: linguagens, práticas e representações. Líder do Experimentações.
}

Como citar esse artigo:

RIBEIRO, Joyce Otânia Seixas; BRÍCIO, Vilma Nonato de. Imagens do corpo: superfícies reversíveis e marcas de resistências no brinquedo de miriti. Revista Digital do LAV, Santa Maria: UFSM, v. 13, n. 2, p. 220-235, mai./ago. 2020. 